\title{
Current data is sufficient to recommend a current standard of care
}

\author{
Paul H. Sugarbaker ${ }^{1}$, Kurt Van der Speeten ${ }^{2}$ \\ ${ }^{1}$ MedStar Washington Hospital Center, Washington, DC, USA; ${ }^{2}$ Department of Surgery, Hospital Oost-Limburg, Genk, Belgium \\ Correspondence to: Paul H. Sugarbaker, MD. MedStar Washington Hospital Center, Washington, DC, USA. Email: Paul.Sugarbaker@outlook.com; \\ Kurt Van der Speeten. Department of Surgery, Hospital Oost-Limburg, Genk, Belgium. Email: Kurt.Vanderspeeten@zol.be. \\ Comment on: Brandl A, Prabhu A. Intraperitoneal chemotherapy in the treatment of gastric cancer peritoneal metastases: an overview of common \\ therapeutic regimens. J Gastrointest Oncol 2021;12:S32-44.
}

Submitted Dec 16, 2020. Accepted for publication Mar 16, 2021.

doi: 10.21037/jgo-2020-10

View this article at: http://dx.doi.org/10.21037/jgo-2020-10

Brandl and Prabhu from Lisbon, Portugal and Tamil Nadu, India, respectively, joined forces to submit our third gastric cancer manuscript (1). Their goal in writing this review was to evaluate many treatment regimens with a goal of consolidation into a few supported by the most reliable data. To their credit, their final paragraph summarizes the NIPEC and HIPEC protocols they recommend for continued utilization and investigation. Interestingly, there was a favorable presentation of the NIPEC protocols to treat advanced PM. This strategy, reported almost exclusively from Asia, utilizes the repeated intraperitoneal administration of a taxane through an intraperitoneal port. The only other treatment option for these patients is systemic chemotherapy. It is not surprising that Brandl and Prabhu suggest that NIPEC paclitaxel can be incorporated into current practice. These authors are confident enough in the RCTs, propensity-adjusted analysis and national registries to recommend as a standard of care gastrectomy, cytoreductive surgery and HIPEC for fit patients with a low peritoneal cancer index and projection of complete cytoreduction by laparoscopic staging. They warn the reader of a large diversity of HIPEC regimens. The Editors would add to their list of usable HIPEC protocols a perioperative combined intraperitoneal and intravenous FLOT, if this regimen was not used as neoadjuvant treatment. This is a great manuscript and worthy of special study.

\section{Acknowledgments}

Funding: None.

\section{Footnote}

Provenance and Peer Review: This article was commissioned by the editorial office, Fournal of Gastrointestinal Oncology for the focused issue "Intraperitoneal Chemotherapy for Peritoneal Metastases: HIPEC, EPIC, NIPEC, PIPAC and More". The article did not undergo external peer review.

Conflicts of Interest: Both authors have completed the ICMJE uniform disclosure form (available at http:// dx.doi.org/10.21037/jgo-2020-10). The focused issue was sponsored by the Peritoneal Surface Oncology Group International (PSOGI). Drs. PHS and KVDS served as the unpaid Guest Editors of the focused issue. The authors have no other conflicts of interest to declare.

Ethical Statement: The authors are accountable for all aspects of the work in ensuring that questions related to the accuracy or integrity of any part of the work are appropriately investigated and resolved.

Open Access Statement: This is an Open Access article 
distributed in accordance with the Creative Commons Attribution-NonCommercial-NoDerivs 4.0 International License (CC BY-NC-ND 4.0), which permits the noncommercial replication and distribution of the article with the strict proviso that no changes or edits are made and the original work is properly cited (including links to both the formal publication through the relevant DOI and the license). See: https://creativecommons.org/

Cite this article as: Sugarbaker PH, Van der Speeten K. Current data is sufficient to recommend a current standard of care. J Gastrointest Oncol 2021;12(Suppl 1):S45-S46. doi: 10.21037/jgo-2020-10 licenses/by-nc-nd/4.0/.

\section{References}

1. Brandl A, Prabhu A. Intraperitoneal chemotherapy in the treatment of gastric cancer peritoneal metastases: an overview of common therapeutic regimens. J Gastrointest Oncol 2021;12:S32-44. 